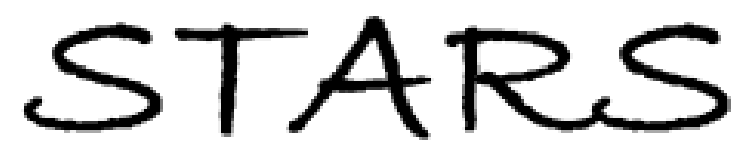

University of Central Florida

STARS

$1-1-2008$

\title{
Review of Introduction to Homeland Security: Understanding Terrorism with an Emergency Management Perspective
}

Naim Kapucu

University of Central Florida

Find similar works at: https://stars.library.ucf.edu/facultybib2000 University of Central Florida Libraries http://library.ucf.edu

This Book Review is brought to you for free and open access by the Faculty Bibliography at STARS. It has been accepted for inclusion in Faculty Bibliography 2000s by an authorized administrator of STARS. For more information, please contact STARS@ucf.edu.

\section{Recommended Citation}

Kapucu, Naim, "Review of Introduction to Homeland Security: Understanding Terrorism with an Emergency Management Perspective" (2008). Faculty Bibliography 2000s. 514.

https://stars.library.ucf.edu/facultybib2000/514

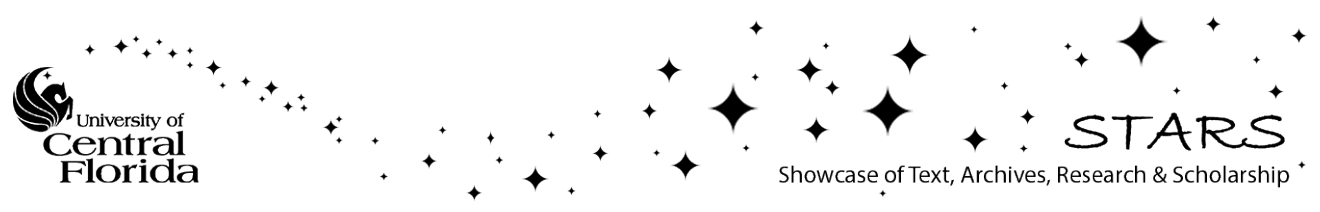




\section{Journal of Homeland Security and Emergency Management}

Volume 5, Issue 1

2008

Article 58

Review of Introduction to Homeland Security: Understanding Terrorism with an Emergency Management Perspective

Naim Kapucu, University of Central Florida

Recommended Citation:

Kapucu, Naim (2008) "Review of Introduction to Homeland Security: Understanding Terrorism with an Emergency Management Perspective," Journal of Homeland Security and Emergency Management: Vol. 5: Iss. 1, Article 58.

DOI: $10.2202 / 1547-7355.1514$ 
Introduction to Homeland Security: Understanding Terrorism with an Emergency Management Perspective by David M. McEntire. 2009. New York: Wiley, 336 pp. ISBN 978-0-470-12752-0; \$54.95.

Review by Naim Kapucu, Ph.D., Associate Professor, University of Central Florida

Homeland security became a significant interest for many in terms of research and education after September 11, 2001. It is defined as "a concerted national effort to prevent terrorist attacks within the United States, reduce America's vulnerability to terrorism, and recover from and minimize the damage of attacks that do occur" (The Office of Homeland Security 2002: 2). Local, state, and federal government, business, and non-profit communities are included in homeland security, and they are being helped by those different participants of homeland security efforts. In order to understand the homeland security, for David McEntire it is important to know that this field is a combination of many areas of study, including: international relations, criminal justice, public administration, political science, and public health. Emergency management includes four functional phases, described as the life cycle of disaster: mitigation/prevention, preparedness, response, and recovery. Since its inception, homeland security has focused most of its attention on so-called crisis management activities, which are prevention, protection, and prosecution activities. Homeland security downplayed preparedness, response, and recovery, which were known as consequence management. Leaders failed to recognize that the US is prone to many different types of hazards.

The emergency management field has become more of a profession compared with the relatively new field of homeland security. Yet the new and emerging field can learn from emergency management. McEntire's book takes this perspective seriously and applies lessons of emergency management to homeland security. The book provides several definitions, common characteristics, and types of terrorism, and the relationship between terrorism and other types of disasters. He uses Quarantelli's (1993) division of disasters into two types: he asserts terrorism as "conflict disaster," a socially disruptive and divisive event that involves a riot or some types of warfare; and "consensus disaster," a socially disruptive event, such as an earthquake, that brings community together. According to Quarantelli, the first type of disaster aims to divide the society, while second type unites.

In homeland security, protection is a proactive activity designed to minimize the possibility and consequences of terrorist attacks. Protection requires a threat assessment of possible attacks that could occur in our nation, states, and 
communities. A threat assessment is a careful study of the targets that might be appealing to terrorists. Critical infrastructure is so vital that their incapacity or destruction would have debilitating impact on the defense or economic security of the United States. Key assets are facilities, sites, and structures that are believed to require additional protection from terrorist attacks. Soft targets are potential sites of terrorist attacks because they are open and accessible to the public. In order to accurately assess the threat of attacks against critical infrastructure, key assets, and soft targets, it will be imperative to work closely with other government agencies, department leaders, and members of the business community who have special knowledge and expertise to help determine the likelihood of an attack along with possible consequences. Such stakeholders, along with their areas of expertise, include: FBI, Department of Defense, Department of Energy, Department of Health and Human Services, Environmental Protection Agency, Department of Agriculture, Department of Treasury, Department of Interior, and Department of Homeland Security.

According to the book, protection against terrorism may require two types of mitigation: structural and non-structural. Structural mitigation involves special construction practices and materials that limit the consequences of terrorist attacks. For instance, installation of blast resistance glass on government buildings is an example of structural mitigation. Non-structural mitigation includes other methods that may limit the possibility of terrorist attacks. Regulations on building location or video surveillance are examples of nonstructural mitigation. There are countless other mitigation measures that can be taken to reduce the probability and consequences of terrorist attacks. Preparedness assumes terrorist attacks will occur and therefore promotes concerted efforts to improve the response and recovery capabilities. Responsibility for national preparedness falls to the federal government in general and to the DHS and FEMA in particular. However, in an attempt to ready the nation for terrorist attacks, the President often issues policies to encourage improved preparedness programs.

There are several other acts, plans, and systems discussed in the book that enhance preparedness: the Post-Katrina Emergency Management Reform Act is a law which specifies ways to avert the slow and disjointed federal response to the catastrophe in New Orleans, Louisiana; the National Incident Management System (NIMS) is a comprehensive national approach for incident management in the United States; the National Response Framework (NRF), successor to the National Response Plan, is a document that describes the principles, roles and structures of response and recovery operations; and the Emergency Management Assistance Compact (EMAC) is an agreement among states to render assistance to one another in time of need. 
McEntire emphasizes the importance of collaboration with key stakeholders in order to be successful in emergency management and terrorism preparedness. Preparedness councils are groups of individuals who provide recommendations for policy and assist with program administration. This kind of council may be comprised of representatives from law enforcement, public health, public works, hospitals, key businesses, the American Red Cross, and volunteer groups, among others. The goal is to ensure that many diverse viewpoints and areas of expertise are incorporated into the preparedness council. Passing local laws are also important for emergency preparedness. In some cases mutual aid will be addressed in the ordinances. Mutual aid is a collaborative agreement between jurisdictions when external help is warranted. Moreover, training, exercises, and community education are vital if a jurisdiction is to be ready to deal with terrorism. Training is information sharing in classroom or field settings to help familiarize people with protocol. It may focus on first responders. There are three types of exercises. There are many ways to share information with the public. Community education, fairs, websites are important media for informing community. Another excellent way to educate citizens is to develop a Community Emergency Management Team (CERT). CERT is a group of citizens who receive basic training in response operations.

Search and Rescue (SAR) is defined by the book as response activities undertaken to find disaster victims and remove them from dangerous confinement. In major events, national Urban Search and Rescue (USAR) teams may be required. FEMA has nearly 30 such teams, made up of fire fighters, engineers, doctors, and paramedics. Victims of an attack generally are affected by the attack at different levels. Consequently, triage may need to be implemented. Triage is the assessment, sorting, treatment, and transportation of the injured to maximize limited medical resources. Moreover, decontamination, the removal of hazardous materials from victims, might be needed. When responding to a terrorist incident involving hazardous materials, three zones should be identified near the attack site. A hot zone is the area which has been contaminated by the terrorist attacks. A warm zone is location where victims are washed. A cold zone is the uncontaminated area. Investigation is a major priority after a terrorist attack. As life safety issues are being addressed, attention can also be shifted toward law enforcement activities. In order to apprehend or prosecute terrorists, evidence must be collected.

Other aspects of emergency management have also been discussed by the author. Warnings are notifications sent out to the public so they can take protective measures. Intelligence is vital for preventing terrorist attacks. And finally, public hearings play an important role in enhancing people's preparedness for any kind of disaster. Evacuations are sometimes needed. Providing sheltering is a vital step to take after evacuation. If people are leaving their homes and 
neighborhoods, they will logically require a place to go. Assessing damages and declaring a disaster are the initial steps to helping communities to recover from a terrorist attack. Damage assessment is a survey of physical destruction and economic losses. It may also look at the number of deaths and amount of social disruption caused by terrorism. There are typically three types of damage assessment rapid assessment, preliminary damage assessment, and technical assessment - as well as different ways of completing them.

The author reminds us of the lessons learned from several disasters about donation management, the collection, sorting, and distribution of goods and money for the benefit of victims of terrorist attacks. The problems resulting from excessive and unrequested donations may be addressed through effective donations management. FEMA set up an office, National Processing Service Center, to help victims apply for the federal assistance programs. Alternatively, victims can go to a disaster recovery center, a temporary facility near the attack location where they can seek information about federal assistance programs. If individual or public assistance is required, community leaders will need to declare a disaster and share damage assessment findings with federal officials. If assistance is deemed as justified, a kickoff meeting will be held. A kickoff meeting is a gathering of local, state, and federal public officials for the purpose of explaining public assistance programs in details.

According to the author, limited vision and poor management have been glaring weaknesses among those responsible for or involved in this national priority. Since its inception, homeland security suffered continual problems. It appears, therefore, that many of the troubles we are currently facing are the results of incorrect planning assumptions as well as ineffective government oversight and follow through. The way to effectively deal with the consequences of terrorism is to enhance response and recovery capabilities. Capacity building is a strategy that attempts to enhance the ability of the nation, states, and communities to effectively deal with potential or actual terrorist attacks. This book is essential reading for students in emergency management and homeland security. It can also be a source for political science and public administration programs with emphasis on emergency management and homeland security.

\section{References:}

Quarentelli, E. (1993). Community Crises: An Exploratory Comparison of the Characteristics and Consequences of Disasters and Riots. Journal of Contingencies and Crisis Management 1 (2): 67-78. 